American Journal of Immunology 8 (2): 44-51, 2012

ISSN 1553-619X

(C) 2012 Science Publications

\title{
Microbial Translocation and B Cell Dysfunction in Human Immunodeficiency Virus Disease
}

\author{
Wei Jiang \\ Department of Microbiology and Immunolog, Deaprtment of Medicine, \\ Division of Infectious Diseases Medical University of South Carolina, \\ 173 Ashly Avenue, Charleston, SC 29425, USA
}

\begin{abstract}
The gut mucosal barrier disrupted in HIV disease, resulting in increased systemic exposure to microbial products such as Lipo Polys Accharide (LPS). The association of enhanced microbial translocation and B cell dysfunction in HIV disease is not fully understood. High dose and short term exposure of microbial Toll-Like Receptor (TLR) agonists were used as vaccine adjuvants, however, low dose and long term exposure of TLR agonists could be harmful. The characteristics of B cell dysfunction in HIV disease included B cell, especially memory B cell depletion, enhanced levels of autoimmune antibodies and impaired vaccine or antigen responsiveness. This review discusses and explores the possibility of the effect of microbial translocation on memory B cell depletion and impaired vaccine responses in HIV infection. By determining the mechanisms of B cell depletion and perturbations in HIV disease, it may be possible to design interventions that can improve immune responses to vaccines, reduce selected opportunistic infections and perhaps slow disease progression.
\end{abstract}

Key words: Microbial translocation, dysfunction, B cell, HIV disease, vaccine, Lipo Polys Accharide (LPS), Toll-Like Receptor (TLR)

\section{INTRODUTION}

HIV epidemiology: Human Immunodeficiency Virus (HIV) is a lentivirus that attacks the human immune system and causes Acquired Immunodeficiency Syndrome (AIDS). The incidence of HIV in the United States is approximately 56, 300 people each year, with the prevalence of HIV infection in the US of about 1,100,000 people (Hall et al., 2008; MMWR, 2006). Approximately 18,000 people with AIDS die each year in the US. There are four major routes of HIV transmission including sex, needles, breast feeding and from mother to her baby at birth (Tsibris and Hirsch. 2010; Grivel et al., 2010). However, until now there is not drug available to completely eliminate HIV virus.

AIDS is a life-threatening condition that can lead to opportunistic infections, cardiovascular and metabolic diseases and cancers. HIV infection leads to the disease of AIDS approximately two to ten years after infection. There are around two to ten years from HIV infection to AIDS. Antiretroviral treatment greatly reduces the mortality and the morbidity of HIV infection (Tsibris and Hirsch. 2010; Grivel et al., 2010). Antiretroviral treatment limits virus under detectable in peripheral blood, other tissues such as lymph nodes, brain and tears still contain varying levels of virus.

Innate and adaptive immunities: There are two types of immune responses in the human system, the innate and adaptive immune responses. The innate immune system has the function to immediately and nonspecifically respond to invading pathogens, including inflammation, complement system and cellular innate responses. For example, dendritic cells produce interferon-alpha in response to virus infection and interferon-alpha has the function of killing the virus (Yoshikai, 2006). When innate immunity cannot eliminate pathogens, adaptive immunity plays a role to control infection. Adaptive immune response defends the host from infection by a specific manner. This means that certain cells of the adaptive immune system recognize and respond to specific pathogens and have specific memories, next time these memory cells can attack the same invading pathogens with a fast and strong response. Innate immunity defenses are immediate and short lasting. Adaptive immunity defenses mount often 1-2 weeks and last longer (Yoshikai, 2006).

Toll-like receptor and its ligands: Toll-Like Receptor (TLR) families are responsible for the recognition of Pathogen-Associated Molecular Patterns (PAMPs) expressed by pathogens and distinguishable from host molecules. TLRs recognize structurally conserved molecules derived from microbes. PAMPs activation links to the innate immune system, results in the production of proinflammatory cytokines and the expression of antimicrobial genes. Activation of 
PAMPs also plays a key role in shaping adaptive immune response. There are more than 10 families of TLR ligands found until now; these TLR ligands include DNA of bacteria, RNA of the virus and Lipo Poly Saccharide (LPS) produced by most Gramnegative bacteria and Gram-positive bacteria. TLR ligands have the function of maintaining normal immune function, however, too much TLR ligands may result in immune activation and cause disease pathogenesis. A certain and low level of TLR ligands in human body is a consequence of living in a non sterile environment, however, the systemic heightened level of TLR ligands are believed to be a consequence of the impaired mucosal integrity, especially in the gut (Abreu, 2010; Fukata and Abreu, 2009).

TLR ligands can be found in bacteria, fungi and also viruses and provide, via TLR binding, early recognition of microbial invasion. TLR1, TLR2 and TLR6 are triggered by peptidoglycan and other microbial products, TLR3 by double-stranded RNA, TLR4 by Lipo Poly Saccharide (LPS), TLR5 by flagellin, TLR7 and TLR8 by imidazoquinolines and TLR9 by unmethylated CpG DNA (Barton and Medzhitov 2003). All TLRs, except TLR3, activate the adaptor Molecule (MyD88) -dependent pathways that culminate in the activation of nuclear factor-kB (NF-kB) transcription factors, as well as the Mitogen-Activated Protein Kinases (MAPKs) extracellular signal-regulated kinase (ERK), p38 and c-Jun N-terminal Kinase (JNK) (Barton and Medzhitov 2003; O’Neill, 2000; 2002a; 2002b). These transcription factors function in concert to promote inflammatory responses (e.g., IL-6, IL-10 and TNF-a) (Lamping et al., 1998; Shen et al., 2008; Soboll et al., 2006). HIV itself is also functional as TLR ligands since RNA sequences derived from the HIV genome are capable of signaling through TLR 7 and TLR 8 (Meier et al., 2007).

Human B lymphocytes and TLRs: Human B lymphocytes produce antibodies against invading pathogens that are key to induce a humoral immune response. Human B cells express high levels of TLR1, TLR6, TLR9 and TLR10, intermediate levels of TLR7 and low levels of TLR2 and TLR4 (Hornung et al., 2002). Most B cell studies focus on TLR9, the main TLR on human B cells, which binds to bacterial DNA (Mansson et al., 2006; Chuang et al ., 2002; Jiang et al., 2007; Martinson et al., 2007; Vollmer et al., 2004). It has been demonstrated recently that switched and IgMpositive memory B cells constitutively express TollLike Receptor 9 (TLR9) (Bernasconi et al., 2003) and it has been suggested that the repeated stimulation through unmetylated $\mathrm{CpG}$ may function to continuously and specifically restimulate $\mathrm{B}$ cells and maintain serologic memory in the absence of traditional protein antigens (Bernasconi et al., 2002). In the model, serum IgG antibodies constitute the specific memory (with B cell receptor signals) built up by previous experience and vaccination and $\operatorname{IgM}$ antibodies may represent first-line memory, indispensable against pathogens never encountered before and T cell Independent (TI) antigens. On the other hand, naïve $\mathrm{B}$ cells are also reported to proliferate and produce $\operatorname{IgM}$ (not IgG) in response to CpG ODN (TLR9 ligand) alone from our previous study and others (Jiang et al., 2007; Bekeredjian-Ding et al., 2005). Furthermore, IgG class switch DNA recombination is induced among human naïve $\mathrm{B}$ cells in response to CpG ODN and IL-10 (He et al., 2004). Thus, TLRs may play a role in the autoimmune diseases those are present in HIV infection. However, the role of TLRs in autoimmune diseases is not clear and is controversial (Lamphier et al., 2006; Papadimitraki et al., 2006). Importantly, TLR ligands enhance antigen-specific B cell responses through B Cell Receptor (BCR) stimulation (Poeck et al., 2004). However, It remains to be demonstrated whether TLRs are important in specific recall reactions induced by either infection or vaccination (TLR ligands as adjuvants).

Chronic immune activation in HIV infection: HIV infection induces broad immune perturbation, including dysfunction and loss of CD4+ $\mathrm{T}$ cells and $\mathrm{B}$ cells (Grossman et al., 2002). Although the HIV virus infects CD4+ $\mathrm{T}$ cell, monocytes/macrophages and dendritic cells, the exact mechanisms of loss of CD4+ T cells, key cells to achieve adaptive humoral and cellular immune responses, are still not fully understood. In HIV infection, there is increasing consensus that immune activation is central to disease pathogenesis (Giorgi et al., 1993). Recent studies suggest that increased microbial products from the damaged gut in chronic HIV infection are at least partially responsible for chronic immune activation (Brenchley et al., 2006; Jiang et al., 2009). High levels of the Toll-like receptor 4 ligand, Lipo Poly Saccharide (LPS) and bacterial ribosomal $16 \mathrm{~S}$ RNA are found in the plasma of individuals with chronic HIV infection. Levels of LPS and 16S rDNA are correlated with indices of immune activation and predict the magnitude of immune restoration after 48 weeks of antiretroviral treatment.

B cell perturbations in HIV disease: B cells are antibody-producing cells; antibodies have the function of killing pathogens. Perturbations of the B cells will result in infection or autoimmune diseases. In HIV disease, there are three main $\mathrm{B}$ cell perturbations including polyclonal $\mathrm{B}$ cell activation, peripheral memory B cell depletion and impaired recall antibody responses (Titanji et al., 2005; 2006; Milito et al., 2000; 
Am. J. Immunol., 8 (2): 44-51, 2012

2004; Guan et al., 2009). Although the lack of CD4+ T cell help may explain some of these deficiencies, there also appear to be intrinsic defects in B lymphocytes that can be demonstrated in functional assays that do not require $\mathrm{T}$ helper cells (Malaspina et al., 2003). The functional defects that have been described in B cells from HIV-infected persons include impaired proliferation responses (to $\mathrm{B}$ cell antigen receptor stimulation, CD40L and $\mathrm{CpG}$ ODNs), reduced antibody production following vaccination, $\mathrm{B}$ cell hyperactivation and hypergammaglobulinemia and increased susceptibility to spontaneous apoptosis (Conge et al., 1998; Malaspina et al., 2008; Moir et al., 2004). B cell hyperactivation in HIV disease may lead to the increased susceptibility of these cells to apoptosis and may also contribute to impaired immune responsiveness.

The effects of B cell depletion and impaired HIVspecific antibodies on SIV/HIV pathogenesis and disease progression are not clear and the results are contradictory (Mao et al., 2005; Miller et al., 2007; McKay et al., 2003; Mestecky et al., 2004; Gaufin et al., 2009). However, B cells are depleted and functionally impaired in pathogenic SIV-infected rhesus macaques, but not in non-pathogenic African green monkeys (Titanji et al., 2005; Dykhuizen et al., 1998; Holznagel et al., 2002; Steger et al., 1998). Nonpathogenic SIV-infected animal models also do not demonstrate gut damage or increased systemic levels of microbial products (Brenchley et al., 2006; Pandrea et al., 2007). B cell apoptosis is rare in non-pathogenic SIV-infected monkeys in the absence of gut enteropathy, B cell apoptosis is present in pathogenic SIV-infected monkeys with microbial translocation, suggesting that B cell death may be induced by HIV infection and microbial translocation.

B cells may also be activated and functionally impaired by HIV itself. It was demonstrated that B cells from HIV-infected viremic patients carry replicationcompetent virus on their surface through CD21, a complement receptor. It was also found that virus bound to B cells could efficiently infect activated CD4 T cells and cause B cell dysfunction (Moir et al., 2001; 2000). There are other mechanisms involved in HIV-associated $\mathrm{B}$ cell dysfunction. HIV interacts with CXCR4 (Feng et al., 2006) on the B cell surface and induces B cell apoptosis. HIV-1 nef protein can activate and stimulate B cells to differentiate (Chirmule et al., 1994; Swingler et al., 2003) as reflected by polyclonal activation (hyperimmunoglobulinmia) in HIV infection (Milito et al., 2004; Nagase et al., 2001). In contrast, a recent study by Qiao et al. (2006) shows that HIV nef protein directly inhibits B cell functional class switches. However, the mechanisms of HIV-associated B cell defects are not completely understood.
Microbial translocation may play an important role in HIV-associated B cell perturbations. Loss of memory B cells and reduced production of antigen-specific antibody is seen in the majority of chronic HIV infection even though the humoral system is subject to repeated and long-term stimulation through TLR agonists released from the gut (Brenchley et al., 2006; Titanji et al., 2006; Milito et al., 2004). This is not only due to desensitization since at the same time there is a B cell polyclonal activation as reflected by increased total IgM and IgG levels (Milito et al., 2004; Nagase et al., 2001). Short-term exposure to TLR ligands (e.g., CpG ODNs) enhances immune responses and has adjuvant effects (Jiang et al., 2007; Malaspina et al., 2008; McCluskie and Krieg, 2006; Krug et al., 2001; Jiang et al., 2005). However, chronic systemic exposure to microbial TLR ligands in HIV disease may have deleterious effects. Nevertheless, humoral immune dysfunction is present differently in HIV disease as reflected by enhanced ex vivo B cell apoptosis with reduced antigen-specific antibody production and polyclonal activation, as compared to other diseases occurring with microbial translocation (e.g., Inflammatory bowel disease) where the autoimmune disease appears to play an important role in immunopathogenesis and gut damage (Kazemi-Shirazi et al., 2002; Roggenbuck et al., 2009). As neither CD4/B lymphopenia nor cell-mediated immune deficiency is recognized concomitants of untreated inflammatory bowel disease (Melmed et al., 2010), it would appear that the virus maintains a central role in cellular and humoral immunodeficiency in HIV infection.

The loss of memory $B$ cells may be related to increased susceptibility of these cells to apoptosis: Spontaneous B cell apoptosis ex vivo as measured by binding of annexin $\mathrm{V}$ is increased in acute and chronic HIV infection (Titanji et al., 2005; Samuelsson et al., 1997). Several cell death signaling pathways has been implicated in HIV infection, such as TNFo/TNFR, TRAIL and Fas/FasL (Lichtner et al., 2004; GasperSmith et al., 2008; Katsikis et al., 1997; Stylianou et al., 2002; Petrovas et al., 2005; Mueller et al., 2001 Nunnari et al., 2005). Moreover, studies by Susan Moir and others indicate that enhanced CD95/Fas expression on B cells in treatment-naïve HIV+ donors is related to B cell apoptosis by exogenous Fas ligand in vitro (Moir et al., 2004). Fas is expressed at low levels on the surface of naïve B cells and enhanced levels in memory B cells (Miyawaki et al., 1992; Schattner and Friedman 1996). In contrast with Fas expression, the expression of Fas ligand is reported to be much more restricted and often requires cell activation. Monocytes or macrophages are capable of producing Fas ligand after activation by opsonizedzymosan or HIV infection in 
vitro (Badley et al., 1996; Brown and Savill, 1999). Importantly, in vivo treatment of anti-Fas ligand $\mathrm{Ab}$ (RNOK203) reduces cell death in circulating B cells from SIV-infected individuals and increases antibody responses to viral proteins (Salvato et al., 2007). Thus, a Fas/FasL-induced cell signal may be involved in B cell death in HIV infection.

Enhanced memory B cell apoptosis may result in impaired antibody responsiveness to vaccination in HIV infection.

A remaining gap in knowledge is the effect of antiretroviral therapy on microbial translocation and B cell restoration. Data from previous studies have shown that the levels of LPS and the 16s RDNA in plasma are significantly reduced after initiation of antiretroviral therapy, but never decrease to normal even among patients with restored normal CD4 counts (Brenchley et al., 2006). Consistent with this, B cell recovery was slower than CD4 $\mathrm{T}$ cell recovery after antiretroviral therapy and was also never restored to normal (Milito, 2004; Terpstra et al., 1989). Although the data relating to HIV-specific IgA are conflicting, it remains clear that the majority of chronically HIV-infected individuals do not mount vigorous HIV-specific IgA antibody responses either locally at mucosal sites or systemically (Mestecky et al., 2004; Broliden et al., 2001 Clerici et al., 2002; Devito et al., 2000a; 2000b).

Although short-term administration of HAART may improve antibody responses (Melvin and Mohan, 2003), long-term administration is still unable to maintain protective levels of antibodies against vaccination antigens like measles, tetanus, influenza and pneumococcus (Titanji et al., 2006; Hart et al., 2007). It suggests that low levels of microbial translocation and HIV RNA in patient plasma after HAART may contribute to the incomplete recovery of antibody responses. The further studies should be designed to be better understood the mechanisms of memory B cell apoptosis in HIV disease. This knowledge would be valuable to improve vaccine responsiveness, decrease opportunistic infections and slow down disease progression.

\section{ACKNOWLEDGEMENT}

This study is supported by grant NIAID R01AI091526.

\section{REFERENCE}

Abreu, M.T., 2010. Toll-like receptor signalling in the intestinal epithelium: How bacterial recognition shapes intestinal function. Nature Rev. Immunol., 10: 131-144. DOI: $10.1038 /$ nri2707
Badley, A.D., J.A. McElhinny, P.J. Leibson, D.H. Lynch and M.R. Alderson et al., 1996. Upregulation of Fas ligand expression by human immunodeficiency virus in human macrophages mediates apoptosis of uninfected T lymphocytes. J. Virol., 70: 199-206. PMID: 8523526

Barton, G.M. and R. Medzhitovm, 2003. Toll-like receptor signaling pathways. Science, 300: 15241525. PMID: 12791976

Bekeredjian-Ding, I.B., M. Wagner, V. Hornung, T. Giese and M. Schnurr et al., 2005. Plasmacytoid dendritic cells control TLR7 sensitivity of naive B cells via type I IFN. J. Immunol., 174: 4043-4050.

Bernasconi, N.L., E. Traggiai and A. Lanzavecchia. 2002. Maintenance of serological memory by polyclonal activation of human memory B cells. Science, 298: 2199-2202. DOI: 10.1126/science. 1076071

Bernasconi, N.L., N. Onai and A. Lanzavecchia, 2003. A role for Toll-like receptors in acquired immunity: up-regulation of TLR9 by BCR triggering in naive $\mathrm{B}$ cells and constitutive expression in memory B cells. Blood, 101: 45004504. PMID: 12560217

Brenchley, J.M., D.A. Price, T.W. Schacker, T.E. Asher and G. Silvestri et al., 2006. Microbial translocation is a cause of systemic immune activation in chronic HIV infection. Nature Med., 12: 1365-1371. DOI: $10.1038 / \mathrm{nm} 1511$

Broliden, K., J. Hinkula, C. Devito, P. Kiama and J. Kimani et al., 2001. Functional HIV-1 specific IgA antibodies in HIV-1 exposed, persistently IgG seronegative female sex workers. Immunol. Lett., 79: 29-36. PMID: 11595287

Brown, S.B. and J. Savill, 1999. Phagocytosis triggers macrophage release of Fas ligand and induces apoptosis of bystander leukocytes. J. Immunol., 162: 480-485. PMID: 9886423

Chirmule, N., N. Oyaizu, C. Saxinger and S. Pahwa. 1994. Nef protein of HIV-1 has B-cell stimulatory activity. AIDS, 8: 733-734. PMID: 8086129

Chuang, T.H., J. Lee, L. Kline, J.C. Mathison and R.J. Ulevitch, 2002. Toll-like receptor 9 mediates CpGDNA signaling. J. Leukocyte Biol., 71: 538-544. PMID: 11867692

Clerici, M., C. Barassi, C. Devito, C. Pastori and S. Piconi et al., 2002. Serum IgA of HIV-exposed uninfected individuals inhibit HIV through recognition of a region within the [alpha] -helix of gp41. AIDS, 16: 1731-1741. PMID: 12218383

Conge, A.M., K. Tarte, J. Reynes, M. Segondy and J. Gerfaux et al., 1998. Impairment of B-lymphocyte differentiation induced by dual triggering of the Bcell antigen receptor and CD40 in advanced HIV1-disease. AIDS, 12: 1437-1449. 
Am. J. Immunol., 8 (2): 44-51, 2012

Devito, C., J. Hinkula, R. Kaul, L. Lopalco and J.J. Bwayo et al., 2000b. Mucosal and plasma $\operatorname{IgA}$ from HIV-exposed seronegative individuals neutralize a primary HIV-1 isolate. AIDS, 14: 1917-1920. PMID: 10997395

Devito, C., K. Broliden, R. Kaul, L. Svensson and K. Johansen et al., 2000a. Mucosal and plasma IgA from HIV-1-exposed uninfected individuals inhibit HIV-1 transcytosis across human epithelial cells. J. Immunol., 165: 5170-5176. PMID: 11046049

Dykhuizen, M., J.L. Mitchen, D.C. Montefiori, J. Thomson and L. Acker et al., 1998. Determinants of disease in the simian immunodeficiency virusinfected rhesus macaque: characterizing animals with low antibody responses and rapid progression. J. General Virol., 79: 2461-2467.

Feng, Z., G.R. Dubyak, M.M. Lederman and A. Weinberg. 2006. Cutting edge: human beta defensin 3--a novel antagonist of the HIV-1 coreceptor CXCR4. J. Immunol., 177: 782-786. PMID: 16818731

Fukata, M. and M.T. Abreu, 2009. Pathogen recognition receptors, cancer and inflammation in the gut. Curr. Opin. Pharmacol., 9: 680-687. DOI: 10.1016/j.coph.2009.09.006

Gasper-Smith, N., D.M. Crossman, J.F. Whitesides, N. Mensali and J.S. Ottinger et al., 2008. Induction of Plasma (TRAIL), TNFR-2, Fas Ligand and Plasma Microparticles after Human Immunodeficiency Virus Type 1 (HIV-1) Transmission: Implications for HIV-1 Vaccine Design. J. Virol., 82: 77007710. DOI: 10.1128/JVI.00605-08

Gaufin, T., M. Pattison, R. Gautam, C. Stoulig and J. Dufour et al., 2009. Effect of B-cell depletion on viral replication and clinical outcome of simian immunodeficiency virus infection in a natural host. J. Virol., 83: 10347-10357. DOI: 10.1128/ JVI.00880-09

Giorgi, J.V., Z. Liu, L.E. Hultin, W.G. Cumberland and K. Hennessey et al., 1993. Elevated levels of CD38+ CD8+ T cells in HIV infection add to the prognostic value of low CD4+ T cell levels: results of 6 years of follow-up. The Los Angeles Center, Multicenter AIDS Cohort Study. J. Acquir. Immune Defic. Syndr., 6: 904-912. PMID: 7686224

Grivel, J.C., R.J. Shattock and L.B. Margolis, 2010. Selective transmission of R5 HIV-1 variants: Where is the gatekeeper? J. Trans. Med. 9: S6-s6. DOI: $10.1186 / 1479-5876-9-S 1-S 6$

Grossman, Z., M. Meier-Schellersheim, A. E. Sousa, R. M. Victorino and W. E. Paul, 2002. CD4 ${ }^{+}$T-cell depletion in HIV infection: are we closer to understanding the cause? Nature Med., 8: 319-323. DOI: $10.1038 / \mathrm{nm} 0402-319$
Guan, Y., M.M. Sajadi, R. Kamin-Lewis, T.R. Fouts and A. Dimitrov et al., 2009. Discordant memory B cell and circulating anti-Env antibody responses in HIV-1 infection. Proceedings of the National Academy of Sciences of the United States of America, Mar. 10. USA, Med. Sci., 106: 39523957. DOI: $10.1073 /$ pnas.0813392106

Hall, H.I., R. Song, P. Rhodes, J. Prejean and Q. An et al., 2008. Estimation of HIV incidence in the United States. JAMA, 300: 520-529. PMID: 18677024

Hart, M., A. Steel, S.A. Clark, G. Moyle and M. Nelson et al., 2007. Loss of discrete memory B cell subsets is associated with impaired immunization responses in HIV-1 infection and may be a risk factor for invasive pneumococcal disease. J. Immunol., 178: 8212-8220. PMID: 17548660

He, B., X. Qiao and A. Cerutti, 2004. CpG DNA induces $\operatorname{IgG}$ class switch DNA recombination by activating human $B$ cells through an innate pathway that requires TLR9 and cooperates with IL-10. J. Immunol., 173: 4479-4491.

Holznagel, E., S. Norley, S. Holzammer, C. Coulibaly and R. Kurth. 2002. Immunological changes in simian immunodeficiency virus $\left(\mathrm{SIV}_{\mathrm{agm}}\right)$-infected African Green Monkeys (AGM): Expanded cytotoxic $\mathrm{T}$ lymphocyte, natural killer and $\mathrm{B}$ cell subsets in the natural host of $\operatorname{SIV}_{\mathrm{agm}}$. J. General Virol., 83: 631-640.

Hornung, V., S. Rothenfusser, S. Britsch, A. Krug and B. Jahrsdorfer et al., 2002. Quantitative expression of toll-like receptor 1-10 mRNA in cellular subsets of human peripheral blood mononuclear cells and sensitivity to $\mathrm{CpG}$ oligodeoxynucleotides. J. Immunol., 168: 4531-4537. PMID: 11970999

Jiang, W., M.M. Lederman, C.V. Harding, B. Rodriguez and R.J. Mohner et al., 2007. TLR9 stimulation drives naïve $B$ cells to proliferate and to attain enhanced antigen presenting function. Eur. J. Immunol., 37: 2205-2213. PMID: 17621369

Jiang, W., M.M. Lederman, J.R. Salkowitz, B. Rodriguez and C.V. Harding et al., 2005. Impaired monocyte maturation in response to $\mathrm{CpG}$ oligodeoxynucleotide is related to viral RNA levels in human immunodeficiency virus disease and is at least partially mediated by deficiencies in alpha/beta interferon responsiveness and productivity. J. Virol., 79: 4109-4119. PMID: 15767412

Jiang, W., M.M. Lederman, P. Hunt, S.F. Sieg and K. Haley et al., 2009. Plasma levels of bacterial DNA correlate with immune activation and the magnitude of immune restoration in persons with antiretroviral-treated HIV infection. J. Infect. Dis., 199: 1177-1185. PMID: 19265479 
Am. J. Immunol., 8 (2): 44-51, 2012

Katsikis, P.D., M.E. Garcia-Ojeda, J.F. Torres-Roca, I.M. Tijoe and C.A. Smith et al., 1997. Interleukin1 beta converting enzyme-like protease involvement in Fas-induced and activation-induced peripheral blood $\mathrm{T}$ cell apoptosis in HIV infection. TNF-related apoptosis-inducing ligand can mediate activation-induced T cell death in HIV infection. J. Exp. Med., 186: 1365-1372. PMID: 9334376

Kazemi-Shirazi, L., C.H. Gasche, S. Natter, A. Gangl and J. Smolen et al., 2002. IgA autoreactivity: A feature common to inflammatory bowel and connective tissue diseases. Clin. Exp. Immunol., 128: 102-109.

Krug, A., A. Towarowski, S. Britsch, S. Rothenfusser and V. Hornunget et al., 2001. Toll-like receptor expression reveals $\mathrm{CpG}$ DNA as a unique microbial stimulus for plasmacytoid dendritic cells which synergizes with CD40 ligand to induce high amounts of IL-12. Eur. J. Immunol., 31: 30263037. PMID: 11592079

Lamphier, M.S., C.M. Sirois, A. Verma, D.T. Golenbock and E. Latz. 2006. TLR9 and the recognition of self and non-self nucleic acids. Annals New York Acad. Sci., 1082: 31-43. PMID: 17145922

Lamping, N., R. Dettmer, N.W. Schroder, D. Pfeil and W. Hallatschek et al., 1998. LPS-binding protein protects mice from septic shock caused by LPS or gram-negative bacteria. J. Clin. Investigation, 101: 2065-2071. PMID: 9593762

Lichtner, M., C. Maranon, P.O. Vidalain, O. Azocar and D. Hanau et al., 2004. HIV type 1-infected dendritic cells induce apoptotic death in infected and uninfected primary CD4 T lymphocytes. AIDS Res. Hum. Retroviruses 20: 175-182. PMID: 15018705

Malaspina, A., S. Moir, A.C. DiPoto, J. Ho and W. Wang et al., 2008. CpG oligonucleotides enhance proliferative and effector responses of B Cells in HIV-infected individuals. J. Immunol., 181: 1199-1206.

Malaspina, A., S. Moir, S. Kottilil, C.W. Hallahan and L. A. Ehler et al., 2003. Deleterious effect of HIV1 plasma viremia on B cell costimulatory function. J. Immunol., 170: 5965-5972. PMID: 12794123

Mansson, A., M. Adner, U. Hockerfelt and L.O. Cardell. 2006. A distinct Toll-like receptor repertoire in human tonsillar B cells, directly activated by PamCSK, R-837 and CpG-2006 stimulation. Immunology, 118: 539-548. PMID: 16780564
Mao, H., B.A. Lafont, T. Igarashi, Y. Nishimura and C. Brown et al., 2005. CD8+ and CD20+ lymphocytes cooperate to control acute simian immunodeficiency virus/human immunodeficiency virus chimeric virus infections in rhesus monkeys: modulation by major histocompatibility complex genotype. J. Virol., 79: 14887-14898. DOI: 10.1128/JVI.79.23.14887-14898.2005

Martinson, J.A., A. Roman-Gonzalez, A.R. Tenorio, C.J. Montoya and C.N. Gichinga et al., 2007. Dendritic cells from HIV-1 infected individuals are less responsive to Toll-Like Receptor (TLR) ligands. Cellular Immunol., 250: 75-84. PMID: 18334250

McCluskie, M.J. and A.M. Krieg, 2006. Enhancement of infectious disease vaccines through TLR9dependent recognition of CpG DNA. Current Top. Microbiol. Immunol., 311: 155-178. DOI: 10.1007/3-540-32636-7_6

McKay, P.F., D.H. Barouch, J.E. Schmitz, R.S. Veazey and D.A. Gorgone et al., 2003. Global dysfunction of CD4 T-lymphocyte cytokine expression in simian-human immunodeficiency virus/SIVinfected monkeys are prevented by vaccination. J. Virol., 77: 4695-4702. DOI: 10.1128/JVI.77.8.4695-4702.2003

Meier, A., G. Alter, N. Frahm, H. Sidhu and B. Li et al., 2007. MyD88-dependent immune activation mediated by human immunodeficiency virus type 1-encoded Toll-like receptor ligands. J. Virol., 81: 8180-8191. PMID: 17507480

Melmed, G.Y., N. Agarwal, R.W. Frenck, A.F. Ippoliti and P. Ibanez et al., 2010. Immunosuppression impairs response to pneumococcal polysaccharide vaccination in patients with inflammatory bowel disease. Am. J. Gastroenterol., 105: 148-154. PMID: 19755964

Melvin, A.J. and K.M. Mohan. 2003. Response to immunization with measles, tetanus and Haemophilus influenza type $b$ vaccines in children who have human immunodeficiency virus type 1 infection and are treated with highly active antiretroviral therapy. Pediatrics, 111: e641-644. PMID: 12777579

Mestecky, J., S. Jackson, Z. Moldoveanu, L.R. Nesbit and R. Kulhavy et al., 2004. Paucity of antigenspecific IgA responses in sera and external secretions of HIV-type 1-infected individuals. AIDS research and human retroviruses 20: 972988. DOI: 10.1089/aid.2004.20.972

Milito, A.D., 2004. B lymphocyte dysfunctions in HIV infection. Curr. HIV Res., 2: 11-21. PMID: 15053337 
Milito, A.D., A. Nilsson, K. Titanji, R. Thorstensson and E. Reizenstein et al., 2004. Mechanisms of hypergammaglobulinemia and impaired antigenspecific humoral immunity in HIV-1 infectious. Blood, 103: 2180-2186. PMID: 14604962

Milito, A.D., B. Hejdeman, J. Albert, S. Aleman, A. Sonnerborg, M. Zazzi and F. Chiodi. 2000. High plasma levels of soluble fas in HIV type 1-infected subjects are not normalized during highly active antiretroviral therapy. AIDS Res. Hum. Retroviruses 16: 1379-1384. PMID: 11018857

Miller, C.J., M. Genesca, K. Abel, D. Montefiori and D. Forthal et al., 2007. Antiviral antibodies are necessary for control of simian immunodeficiency virus replication. J. Virol., 81: 5024-5035. DOI: 10.1128/JVI.02444-06

Miyawaki, T., T. Uehara, R. Nibu, T. Tsuji and A. Yachieet et al., 1992. Differential expression of apoptosis-related Fas antigen on lymphocyte subpopulations in human peripheral blood. J. Immunol., 149: 3753-3758.

MMWR, 2006. Epidemiology of HIV/AIDS--United States, 1981-2005. Weekly, 55: 589-592.

Moir, S., A. Malaspina, K.M. Ogwaro, E.T. Donoghue and C.W. Hallahan et al., 2001. HIV-1 induces phenotypic and functional perturbations of B cells in chronically infected individuals. Proceedings of the National Academy of Sciences of the United States of America. (NASUSA' 01) USA, The National Academy of Sciences, 98: 10362-10367. DOI: 10.1073/pnas.181347898

Moir, S., A. Malaspina, O.K. Pickeral, E.T. Donoghue and J. Vasquez et al., 2004. Decreased survival of $\mathrm{B}$ cells of HIV-viremic patients mediated by altering expression of receptors of the TNF superfamily. The Journal of experimental medicine 200: 587-599. DOI: 10.1084/ jem. 20032236

Moir, S., A. Malaspina, Y. Li, T.W. Chun and T. Lowe et al., 2000. B cells of HIV-1-infected patients bind virions through CD21-complement interactions and transmit infectious virus to activate T cells. J. Exp. Med., 192: 637-646. DOI: 10.1084/jem.192.5.637

Mueller, Y.M., S.C. De Rosa, J.A. Hutton, J. Witek and M. Roederer et al., 2001. Increased CD95/FasInduced Apoptosis of HIV-Specific CD8+ T Cells. Immunity, 15: 871-882. DOI: 10.1016/S10747613(01)00246-1

Nagase, H., K. Agematsu, K. Kitano, M. Takamoto and Y. Okuboet et al., 2001. Mechanism of hypergammaglobulinemia of HIV infection: circulating memory B-cell reduction with plasmacytosis. Clin. Immunol., 100: 250-259. PMID: 11465955
Nunnari, G., Y. Xu, E.A. Acheampong, J. Fang and R. Daniel et al., 2005. Exogenous IL-7 induces Fasmediated human neuronal apoptosis: potential effects during human immunodeficiency virus type 1 infection. J. Neurovirol., 11: 319-328. DOI: $10.1080 / 13550280500187005$

O'Neill, L.A., 2000. The interleukin-1 receptor/Tolllike receptor superfamily: Signal transduction during inflammation and host defense. Sci. STKE. PMID: 11752602

O’Neill, L.A., 2002a. Toll-like receptor signal transduction and the tailoring of innate immunity: A role of Mal? Trends Immunol., 23: 296-300. PMID: 12072368

O'Neill, L.A., 2002b. Signal transduction pathways activated by the IL-1 receptor/toll-like receptor superfamily. Current Top. Microbiol. Immunol., 270: 47-61. PMID: 12467243

Pandrea, I.V., R. Gautam, R.M. Ribeiro, J.M. Brenchley and I.F. Butler et al., 2007. Acute loss of intestinal CD4+ $\mathrm{T}$ cells is not predictive of simian immunodeficiency virus virulence. $\mathrm{J}$. Immunol., 179: 3035-3046. PMID: 17709518

Papadimitraki, E.D., C. Choulaki, E. Koutala G. Bertsias and C. Tsatsanis et al., 2006. Expansion of toll-like receptor 9-expressing $B$ cells in active systemic lupus erythematosus: Implications for the induction and maintenance of the autoimmune process. Arthritis Rheum., 54: 3601-3611. PMID: 17075805

Petrovas, C., Y. M. Mueller and P. D. Katsikis. 2005. Apoptosis of HIV-specific CD8+ T cells: an HIV evasion strategy. Cell Death Differ., 12: 859-870. DOI: $10.1038 /$ sj.cdd.4401595

Poeck, H., M. Wagner, J. Battiany, S. Rothenfusser and D. Wellisch et al., 2004. Plasmacytoid dendritic cells, antigen and CpG-C license human B cells for plasma cell differentiation and immunoglobulin production in the absence of T-cell help. Blood, 103: 3058-3064. PMID: 15070685

Qiao, X., B. He, A. Chiu, D.M. Knowles and A. Chadburn et al., 2006. Human immunodeficiency virus 1 Nef suppresses CD40-dependent immunoglobulin class switching in bystander B cells. Nature Immunol., 7: 302-310. DOI: 10.1038/ni1302

Roggenbuck, D., G. Hausdorf, L. Martinez-Gamboa, D. Reinhold and T. Buttner et al., 2009. Identification of GP2, the major zymogen granule membrane glycoprotein, as the autoantigen of pancreatic antibodies in Crohn's disease. Gut 58: 1620-1628. DOI: 10.1136/gut.2008.162495 
Salvato, M.S., C.C. Yin, H. Yagita, T. Maeda and K. Okumura et al., 2007. Attenuated disease in SIVinfected macaques treated with a monoclonal antibody against FasL. Clin. Developmental Immunol., 2007: 93462-934629 DOI: 10.1155/2007/93462

Samuelsson, A., C. Brostrom, N. van Dijk, A. Sonnerborg and F. Chiodi. 1997. Apoptosis of CD4+ and CD19+ cells during human immunodeficiency virus type 1 infection-correlation with clinical progression, viral load and loss of humoral immunity. Virology 238: 180-188.

Schattner, E. and S.M. Friedman, 1996. Fas expression and apoptosis in human B cells. Immunol Res., 15: 246-257. DOI: $10.1007 / \mathrm{BF} 02918252$

Shen, K.H., C.H. Lin, H.K. Chang, W.C. Chen and S.H. Chen. 2008. Premarin can act via estrogen receptors to rescue mice from heatstroke-induced lethality. Shock, 30: 668-674. DOI: 10.1097/SHK.0b013e31817538cb

Soboll, G., L. Shen and C. R. Wira. 2006. Expression of Toll-Like Receptors (TLR) and responsiveness to tlr agonists by polarized mouse uterine epithelial cells in culture. Biology of reproduction 75:131139. DOI: 10.1095/biolreprod.106.050690

Steger, K.K., M. Dykhuizen, J.L. Mitchen, P.W. Hinds and B.L. Preuninger et al., 1998. CD4+-T-cell and CD20+-B-cell changes predict rapid disease progression after simian-human immunodeficiency virus infection in macaques. J. Virol., 72: 1600-1605.

Stylianou, E., A. Yndestad, L.I. Sikkeland, V. Bjerkeli and J.K. Damas et al., 2002. Effects of interferonalpha on gene expression of chemokines and members of the tumor necrosis factor superfamily in HIV-infected patients. Clin. Exp. Immunol., 130: 279-285. PMID: 12390316
Swingler, S., B. Brichacek, J. M. Jacque, C. Ulich, J. Zhou and M. Stevenson. 2003. HIV-1 Nef intersects the macrophage CD40L signalling pathway to promote resting-cell infection. Nature, 424: 213-219. PMID: 12853962

Terpstra, F.G., B.J. Al, M.T. Roos, F. De Wolf and J. Goudsmit et al., 1989. Longitudinal study of leukocyte functions in homosexual men seroconverted for HIV: rapid and persistent loss of B cell function after HIV infection. Eur. J. Immunol., 19: 667-673. DOI: 10.1002/eji.1830190415

Titanji, K., A. De Milito, A. Cagigi, R. Thorstensson and S. Grutzmeier et al., 2006. Loss of memory B cells impairs maintenance of long-term serologic memory during HIV-1 infection. Blood, 108: 15801587. PMID: 16645169

Titanji, K., F. Chiodi, R. Bellocco, D. Schepis and L. Osorio et al., 2005. Primary HIV-1 infection sets the stage for important B lymphocyte dysfunctions. AIDS, 19: 1947-1955. DOI: 10.1186/1742-4690-2S1-P95

Tsibris, A.M. and M.S. Hirsch. 2010. Antiretroviral therapy in the clinic. J. Virol., 84: 5458-5464. PMID: 20181709

Vollmer, J., R. Rankin, H. Hartmann, M. Jurk and U. Samulowitz et al., 2004. Immunopharmacology of $\mathrm{CpG}$ oligodeoxynucleotides and ribavirin. Antimicrobial Agents Chemotherapy, 48: 23142317. DOI: 10.1128/AAC.48.6.2314-2317.2004

Yoshikai, Y., 2006. Crosstalk between innate and adaptive immunity. Nihon Rinsho, 64: 1223-1228. PMID: 16838637 